\title{
Examining the Role of Fairness in High Stakes Allocation Decisions*
}

\author{
John A. List \\ University of Maryland and NBER \\ Todd L. Cherry \\ Appalachian State University
}

19 July 2003

\begin{abstract}
Recent experimental evidence has led to a debate about the nature of utility functions in which people are concerned about the amount others earn, and what factors heighten or diminish social preference. We explore fairness by examining behavior across three variants of the dictator game. Using data from nearly 200 dictators allocating as much as $\$ 100$ each, we observe that fairness considerations are very powerful-when subjects could reasonably believe that disproportionately low offers are "fair", only 8-12 percent of dictators make positive offers. Examining the comparative static results from these allocation decisions, we find that recent theoretical models of inequality do a respectable job of explaining the data patterns.

JEL: C7, C9

Key words: allocation decisions, fairness, earned wealth

Correspondence:

John A. List, Professor, The University of Maryland, 2200 Symons Hall, College Park, MD 20742-5535, email: Jlist@arec.umd.edu; website: http://www.arec.umd.edu/jlist

\footnotetext{
*Thanks to David Grether and an anonymous reviewer for helpful comments. Colin Camerer, Ernst Fehr, Liesl Koch, Kevin McCabe and Vernon Smith also provided useful comments. We acknowledge the financial support from a summer research grant, University of Central Florida, and Dean Thomas Keon. Apinya Thumaphipol and Priti Manek provided able research assistance. The usual caveats apply.
} 
Important predictions from the game-theoretic literature are frequently rather extreme, leading expectations to be oftentimes unmet. Perhaps the most well known example in the economics literature is a class of games that includes the popular ultimatum and dictator variants. ${ }^{1}$ Although the dictator game arguably presents the simplest possible strategy space for subjects to understand, proposers do not ubiquitously send zero dollars to their partner (Camerer and Thaler, 1995). Many authors have attempted to clarify this behavior by examining individual behavior within a theoretical framework. This important line of research includes inequality models due to Bolton and Ockenfels (2000) and Fehr and Schmidt (1999), as well as Andreoni et al.'s (1998) road map for building a more predictive model of fairness. ${ }^{2}$

Inextricably related to these studies is an influential line of research that suggests there is a critical link between social isolation and Nash play in bargaining games (e.g., Hoffman et al., 1994, hereafter HMSS). The experimental design in this line of work permits an examination of the comparative static effect of varying social isolation while holding the level of "fairness" constant. Reported results suggest that many individuals become Nash players as social isolation increases.

Rather than examining the effect of changes in social isolation, in this note we hold social isolation constant and examine the comparative static effect of varying degrees of perceived fairness. We accomplish this goal by analyzing decisions from

\footnotetext{
${ }^{1}$ The ultimatum game is a two-stage game where two people, a proposer and a responder, bargain over a fixed amount of money. In the first stage, the proposer offers a split of the money, and in the second stage, the responder decides to accept or reject the offer. If accepted, each player receives money according to the offer; if rejected, each player receives no money. The dictator game is a simple variant of the ultimatum game. In the dictator game, strategic concerns are absent as the proposer simply states what the split will be and the proposer has no veto power, rendering the proposed split as effective.

${ }^{2}$ The Bolton and Ockenfels (2000) and Fehr and Schmidt (1999) models provide similar predictions except with respect to stakes.
} 
nearly 200 subjects in dictator games that varied the level of stakes from $\$ 20$ to $\$ 100$ and varied the degree of "fairness" associated with disproportionately low offers. Perceived fairness was varied by moving from the typical dictator baseline treatment to asymmetric and symmetric designs that served to allocate initial wealth based on individual proficiency on a 45-minute quiz. In the asymmetric treatment, only the dictator was afforded the opportunity to earn wealth, whereas in the symmetric treatment both the dictator and responder had a chance to earn money.

Our data provide three major insights. First, the earnings component induced dictators to exhibit a considerably higher rate of self-interested behavior than previously reported (see, e.g., Forsythe et al., 1994; HMSS, 1994; Bohnet and Frey, 1999). In the limit, we observe that only 8-12 percent of dictators make positive offers. Second, increasing the stakes from $\$ 20$ to $\$ 100$ does not appreciably alter allocation decisions. Finally, certain aspects of our results are explained well by the comparative static predictions found in recent theoretical models of inequality.

\section{Experimental Design and Hypotheses}

Subjects that were unfamiliar with experimental games were recruited from the undergraduate student body at a large university in the U.S. We conducted three sessions: a baseline treatment that was identical to the HMSS baseline and two earnings treatments: an asymmetric (77 pairs) and a symmetric (78 pairs) treatment. In all respects we were careful to follow identical procedures in each session to ensure that the parameter social isolation remained constant, thus ensuring that any notion of strategic reciprocity would not change across treatments. Participants were randomly assigned to two groups, with one placed in room A and the other placed in room B. The two groups 
did not have any contact before, during, or after the session. Within each group, subjects were allowed to talk only to administrators. Each treatment had at most two stages earnings and allocation - and each had a written protocol to ensure consistency. As is typical, no subject participated in more than one treatment, thus our results rely on purely between-subject variation.

The Earnings Stage informed the designated group(s) that they would earn money by taking a quiz before moving to the second, and final, stage of the experiment. Subjects were informed that a simple rule would determine their earnings in the first stage of the experiment: if they answered 10 or more questions correctly they would receive $\$ 100$; if they answered fewer than 10 questions correctly they would receive $\$ 20 .^{3}$ After addressing all questions, subjects were informed that they had 45 minutes to complete the quiz. After the allotted time elapsed, the quiz was collected and graded.

The Allocation Stage randomly matched subjects across groups with the person in room A being the first-mover (proposer). Instructions for the dictator game were read aloud to both groups and all questions were addressed. The allocation (dictator) games were one-shot, and were done over the first-mover's earnings. To conclude, final earnings were determined and subjects departed individually with cash payment.

An asymmetric earnings design provides our initial deviation from the baseline. In this treatment, only subjects assigned to room A participated in the earnings session. Subjects in room A were informed that "the person in Room B has not had the opportunity to earn any money." For time management, subjects assigned to room B arrived one hour after those assigned to room A. The next deviation from the baseline is

\footnotetext{
${ }^{3}$ The quiz is taken verbatim from List and Cherry (2000).
} 
a symmetric earnings treatment. In the symmetric earnings treatment, all subjects (rooms A and B) participated in the earnings session. Subjects in both rooms were informed that "people in rooms A and B have earned an amount of money by participating in identical sessions." Subjects in both rooms were further informed that "the person in room B does not decide how to split his or her earnings—-he or she keeps all of the earnings."

Given the dichotomous outcome of the earnings session, we are provided with an opportunity to test the difference between low $(\$ 20)$ and high $(\$ 100)$ stakes within the two treatment types. Our experimental design is summarized in Table 1, with treatments sub-categorized as baseline with low (high) stakes, $\mathrm{B} \$ 20(\mathrm{~B} \$ 100)$, and asymmetric (symmetric) earnings with low stakes, $\mathrm{A} \$ 20$ ( $\$ \$ 20)$, and asymmetric (symmetric) earnings with high stakes, $\mathrm{A} \$ 100$ ( $\mathrm{S} \$ 100)$. Table 1 also provides sample sizes across the cells, which tend to be larger than previous studies and suggest that more than half of the subjects earned the right to distribute $\$ 100-43$ out of 77 (41 out of 78 ) in the asymmetric (symmetric) treatment answered 10 or more of the 17 questions correctly.

Making $F(\bullet)$ the population distribution of offers, our series of main null hypotheses take the form $H_{o}: F\left(\mathrm{~T}_{\mathrm{i}} \$ \mathrm{Z}\right)=F\left(\mathrm{~T}_{\mathrm{j}} \$ \mathrm{Z}\right)$, where $\mathrm{i}, \mathrm{j}$ are treatment indicators for baseline, asymmetric, and symmetric, and $\mathrm{i} \neq \mathrm{j}$; and $\mathrm{Z}$ represents stakes, therefore $\mathrm{Z}=$ $\$ 20, \$ 100$. A secondary null hypothesis of interest concerns stakes: $H_{0}: F\left(\mathrm{~T}_{\mathrm{i}} \$ 20\right)=$ $F\left(\mathrm{~T}_{\mathrm{i}} \$ 100\right)$. Rejecting the first null hypothesis in favor of the appropriate one-sided alternative suggests that relaxing the "fairness" constraint induces behavior more in line with the standard equilibrium prediction. Concerning the secondary null hypotheses, if we reject the null, inference would be that stakes and allocation behavior are correlated. This would provide evidence of the predictive power of the Fehr and Schmidt (1999) 
model, which predicts giving should increase with higher stakes (the model of Bolton and Ockenfels (2000) is agnostic on this issue).

\section{Experimental Results}

Table 2 summarizes the individual data obtained from our three dictator games. Figures 1-3 use these data to graphically depict the frequency distribution for each treatment. Of first note is the finding that our baseline experimental data are qualitatively equivalent to results reported in other dictator games. For example, our data are in large part consistent with the data reported in, for example, Hoffman et al. (1996), Eckel and Grossman (1996), and Bohnet and Frey (1999), as we find that rates of positive offers, equal splits, and average positive offers are in the range of 50 percent, 20 percent, and 30 percent.

Moving to our stakes hypotheses, we find that although the summary statistics in Table 2 and the figures suggest there are differences between the data across the $\$ 20$ and $\$ 100$ treatments, using a Wilcoxon nonparametric test we cannot reject the null hypothesis that the distributions are identical across stakes conditions in the baseline, asymmetric, or symmetric treatments at the conventional $\mathrm{p}<.05$ level. ${ }^{4}$ Although the increase in stakes appears to push the distributions rightward, suggesting dictators in high stakes games tend to offer more than dictators in low stakes games, this effect is not significant. ${ }^{5}$ Directionally, this finding is in line with the Fehr and Schmidt (1999)

\footnotetext{
${ }^{4}$ Given that this test may lack power (see, e.g., Forsythe et al., 1994), we also tested for distributional differences using a Kolmogorov-Smirnov (KS) test. In each case, we could not reject the null hypothesis of identical distributions at even the $\mathrm{p}=.50$ level using the KS test.

${ }^{5}$ This finding is consistent with Forsythe et al.'s (1994) dictator game results and List and Cherry's (2000) ultimatum game data. We should note, however, a potentially important caveat: since results from the quiz determined the stakes each individual allocated, there is a potential selection issue that could be an important influence on the reported results. Future research should examine whether our results are robust to randomly allocating subjects to stake levels (while preserving the "earned" nature of the position).
} 
model, which predicts less giving by $\$ 20$ earners compared to those who earned $\$ 100$. Yet, given that there is so little variation in the data, this prediction cannot be tested with a substantial amount of power. Given that the stakes treatment did not significantly alter allocation decisions, we pool the $\$ 20$ and $\$ 100$ data for the statistical analysis below.

Comparing data across the baseline and earnings treatments provides an interesting contrast. Whereas our baseline treatments yield data in the spirit of the existing literature, dictators acting over earned wealth have distributions shifted toward lower offers in each case. Figures 1-3 show the declination of offers as we move toward the treatments that fully relax the "fairness" constraint. Wilcoxon nonparametric tests reinforce what the naked eye can readily see: although the asymmetric earnings and baseline distributions are not different from one another at conventional levels $(\mathrm{z}=1.14)$, we can reject equivalency of the symmetric and baseline distributions at the $p<.01$ level $(\mathrm{z}=3.24)$. In addition, we find that the asymmetric and symmetric treatments yield different distributions at better than the $\mathrm{p}<.01$ level $(\mathrm{z}=2.70)$.

Similar inference obtains when we consider the proportion of dominant strategy play (giving 0 ). In contrast to the 50-55 percent of theoretically correct play observed in our baseline treatments, dictators acting over asymmetric earnings followed theory in 5871 percent of the allocation decisions. The movement toward the standard equilibrium prediction continued when dictators acted over symmetric earnings - in 88-92 percent of cases dictators kept everything for themselves. According to a test of proportions, these differences in theoretically correct play between the symmetric and baseline (asymmetric) treatment are each significantly different from zero at the $p<.01$ level 
(symmetric vs. baseline: $\mathrm{z}=4.55$; symmetric vs. asymmetric: $\mathrm{z}=3.85$ ). ${ }^{6}$ Furthermore, in the symmetric treatment, the proportion of zero offers was not significantly different from 100 percent at conventional significance levels $(\mathrm{z}=1.82)$.

While it would be easy to claim that earning entitlements (or property rights) matter, we feel that at best the effect is modest, and in fact not statistically significant. This interpretation follows from a comparison between the asymmetric and baseline treatments, which provide behavior that is not statistically distinguishable. This finding is different from the data reported in Hoffman and Spitzer (1985) and HMSS (1994), who find results that suggest earning, rather than being randomly assigned, the first-mover position mitigates the influence of social norms that may lead to other-regarding behavior. Our results suggest that an important disparity may exist between the underlying notion of earning the property right of a social position and earning wealth.

Our experimental design is sufficiently rich to allow one final test of existing theories of social utility. In our view, a descriptive model of social utility should yield predictions about when fairness or inequality should matter a great deal, leading to large deviations from self-interest, and when behavior should be consistent with self-interest. In this regard, certain extant theories describe an important aspect of our data. When comparing results across the asymmetric and symmetric designs, we find that the Bolton and Ockenfels' (2000) and Fehr and Schmidt (1999) models have a good deal of

\footnotetext{
${ }^{6}$ Table 2 also reports that the frequency of equal splits decreased dramatically when the "fairness" aspect was relaxed. While the baseline treatment observed equal splits in 25 and 15 percent of allocation decisions, equal splits occurred in only 9 percent $(7$ of 77) of the asymmetric allocation decisions and only 5 percent ( 4 of 78 ) of the symmetric earnings allocation decisions.
} 
predictive power-giving is significantly lower in the symmetric treatment, as predicted by their inequality aversion theories. ${ }^{7}$

\section{Conclusion}

The importance of experimental results from allocation games is more than academic curiosity, as some scholars believe certain results may represent a fatal flaw in standard economic theory - the commonly coined "fall of homo-economicus." In this study, we presented experimental results from an allocation game in which subjects earned initial wealth. Examining experimental data from nearly 200 subjects in dictator games that varied the level of stakes from $\$ 20$ to $\$ 100$ and varied the degree of "fairness" associated with disproportionately low offers, we found that fairness considerations are quite strong: only 8-12 percent of dictators made positive offers when the fairness constraint was sufficiently relaxed. Our data also suggest that neither an increase in stakes (from $\$ 20$ to $\$ 100$ ) nor the entitlement property considerably influenced allocation decisions. Finally, certain patterns in our data are consonant with comparative static predictions of recent inequality models. ${ }^{8}$

\footnotetext{
${ }^{7}$ These models also predict that giving should be greater in $\mathrm{S} \$ 100$ versus $\mathrm{S} \$ 20$. While the data are not consonant with this prediction, it should be stressed that since dictators did not know the probability weights over their partner's allocation this test is not clean.

${ }^{8}$ While our data suggest that fairness matters, the literature has pointed to several other aspects that influence behavior as well (see, e.g., Nelson's (2002) ultimatum game study).
} 


\section{References}

Andreoni, James, Brown, Paul, and Vesterlund, Lise. "What Produces Fairness? Some Experimental Evidence." Working paper, 1998, University of Wisconsin.

Bohnet, Iris, and Frey, Bruno S. "Social Distance and Other-Regarding Behavior in Dictator Games: Comment." American Economic Review, March 1999, 89(1), pp. 335-339.

Bolton, Gary, and Ockenfels, Axel. "ERC: A Theory of Equity, Reciprocity, and Competition." American Economic Review, 2000, 90, pp. 166-193.

Camerer, Colin F., and Thaler, Richard H. "Anomalies: Ultimatums, Dictators and Manners." Journal of Economic Perspectives, 1995, 9:2 (Spring), 209-219.

Eckel, Catherine C., and Grossman, Philip J. "Altruism in Anonymous Dictator Games." Games and Economic Behavior, October 1996, 16(2), pp. 181-191.

Fehr, Ernst, and Schmidt, Klaus M. "A Theory of Fairness, Competition, and Cooperation." Quarterly Journal of Economics, 1999, 114, pp. 817-868.

Forsythe, Robert, Horowitz, Joel L., Savin, N.E., and Sefton, Martin. "Fairness in Simple Bargaining Experiments." Games and Economic Behavior, May 1994, 6(3), pp. 347-369.

Hoffman, Elizabeth, McCabe, Kevin, Shachat, Keith, and Smith, Vernon L. "Preferences, Property Rights and Anonymity in Bargaining Games." Games and Economic Behavior, November 1994, 7(3), pp. 346-380.

Hoffman, Elizabeth, McCabe, Kevin, and Smith, Vernon L. "Social Distance and OtherRegarding Behavior in Dictator Games." American Economic Review, June 1996, 86(3), pp. 653-660.

Hoffman, Elizabeth, and Spitzer, Matthew. "Entitlements, Rights, and Fairness: An Experimental Examination of Subjects' Concepts of Distributive Justice." Journal of Legal Studies, 1985, 15, pp. 254-297.

List, John A., and Cherry, Todd L. "Learning to Accept in Ultimatum Games: Evidence from an Experimental Design that Generates Low Offers." Experimental Economics, 2000, 3(1), pp. 11-29.

Nelson, William R. Jr. "Equity or Intention: it is the Thought that Counts," Journal of Economic Behavior \& Organization, 2002 48(4), pp. 423-430. 
Table 1 Experimental Design

\begin{tabular}{llll}
\hline Treatment (n) & Game & Earnings & Stakes \\
\hline B $\$ 20(20)$ & Dictator & None & $\$ 20$ \\
B $\$ 100(20)$ & Dictator & None & $\$ 100$ \\
A $\$ 20(34)$ & Dictator & Asymmetric & $\$ 20$ \\
A $\$ 100(43)$ & Dictator & Asymmetric & $\$ 100$ \\
S\$20(37) & Dictator & Symmetric & $\$ 20$ \\
S\$100 $(41)$ & Dictator & Symmetric & $\$ 100$ \\
\hline
\end{tabular}

Table 2 Aggregate Behavior

\begin{tabular}{lccc}
\hline Treatment (n) & $\begin{array}{c}\text { Rate of } \\
\text { Positive Offers }\end{array}$ & $\begin{array}{c}\text { Rate of } \\
\text { Equal Splits }\end{array}$ & $\begin{array}{c}\text { Average } \\
\text { Positive Offer* }\end{array}$ \\
\hline B \$20 (20) & 0.5000 & 0.2500 & 0.3300 \\
B\$100 (20) & 0.4500 & 0.1500 & 0.2831 \\
A \$20 (34) & 0.2941 & 0.1176 & 0.3600 \\
A \$100 (43) & 0.4186 & 0.0697 & 0.2083 \\
S\$20 (37) & 0.0811 & 0.0541 & 0.4333 \\
S\$100 (41) & 0.1220 & 0.0488 & 0.3100 \\
\hline
\end{tabular}

*reported as percentage of total amount available in the allocation decision (average positive offer ignores zero-offers). 
Figure 1A. Experiment B\$20 (Dictator Baseline with Unearned \$20)

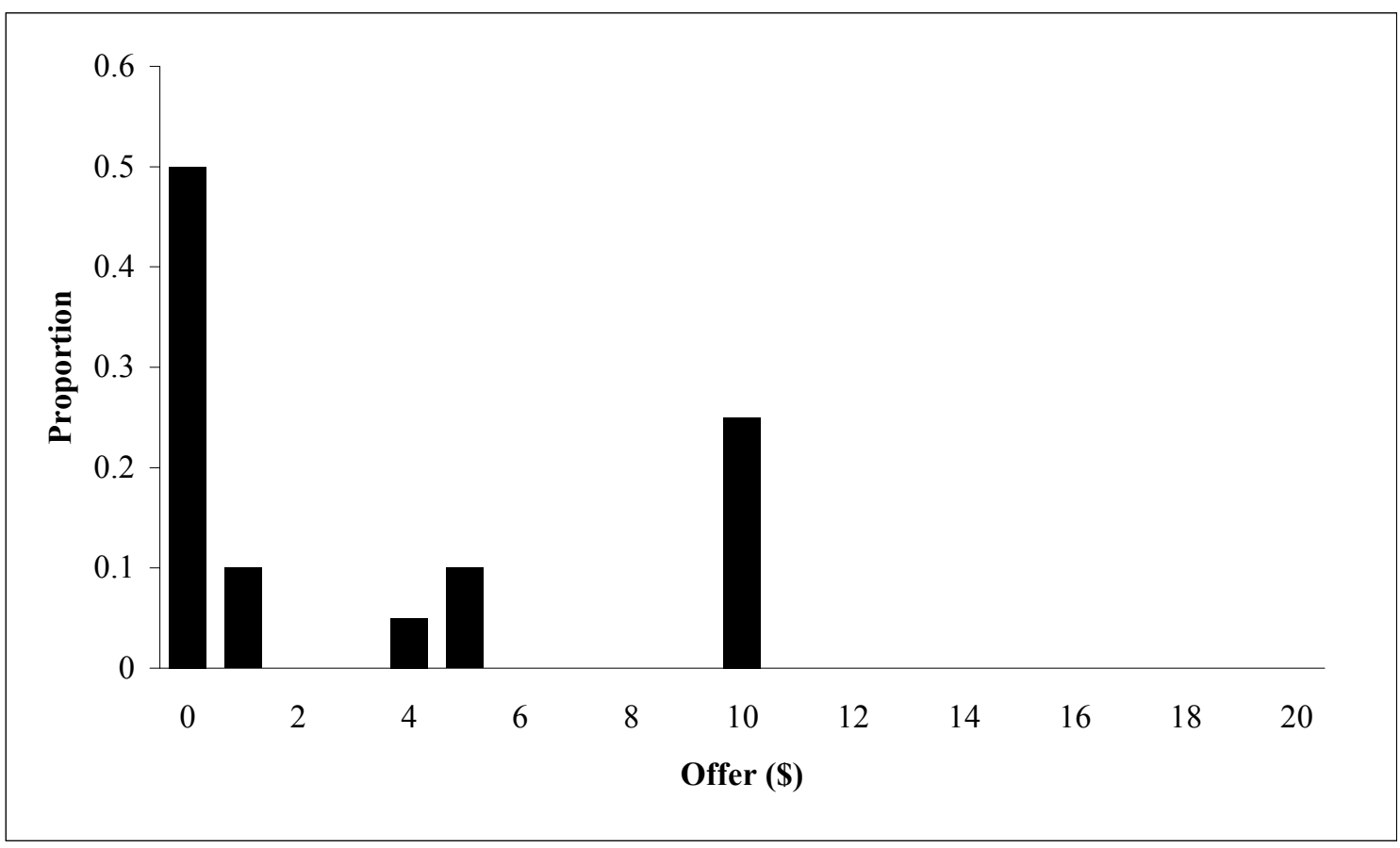

Figure 1B. Experiment B \$100 (Dictator Baseline with Unearned \$100)

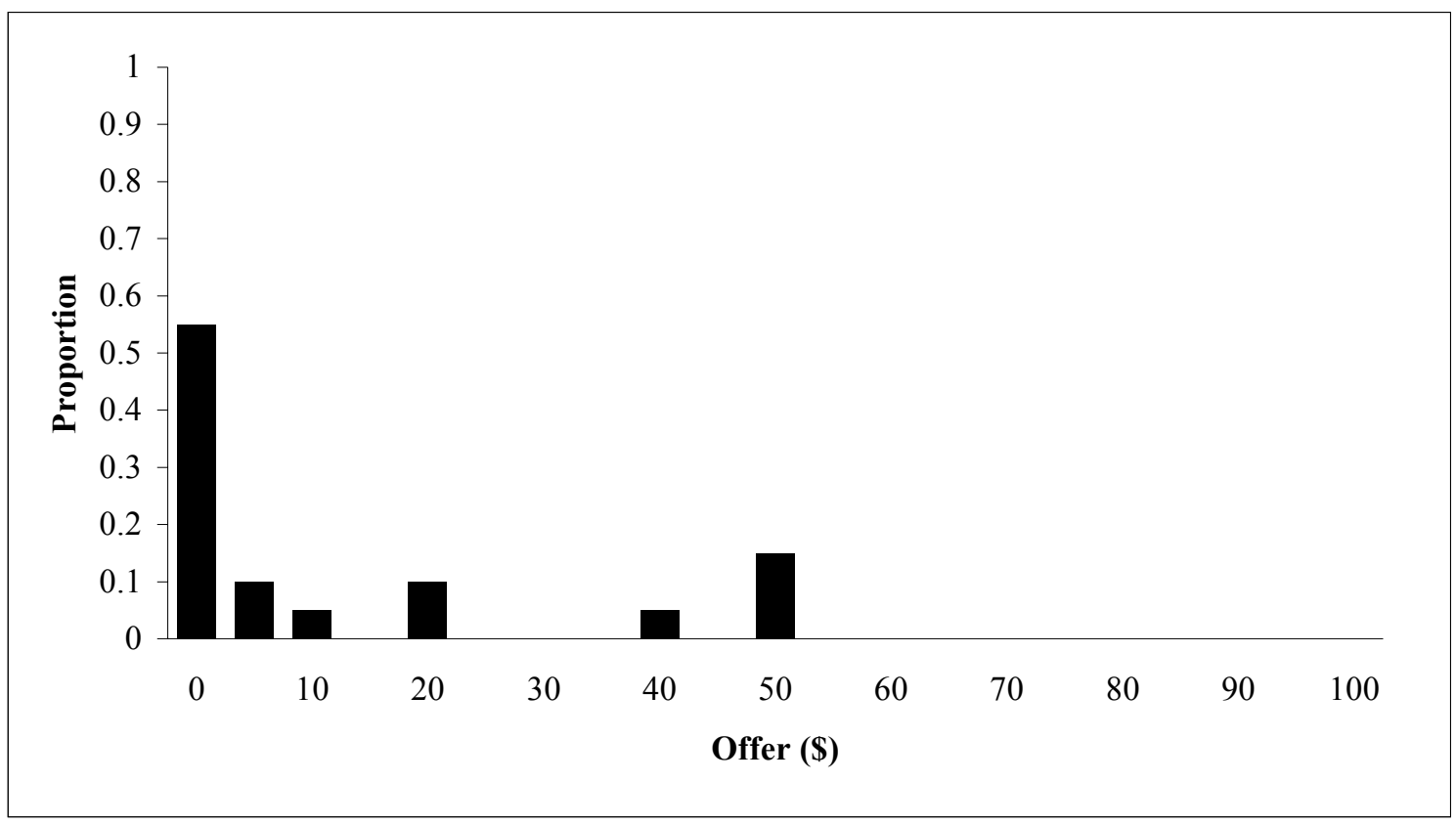


Figure 2A. Experiment A\$20 (Asymmetric Earnings of \$20)

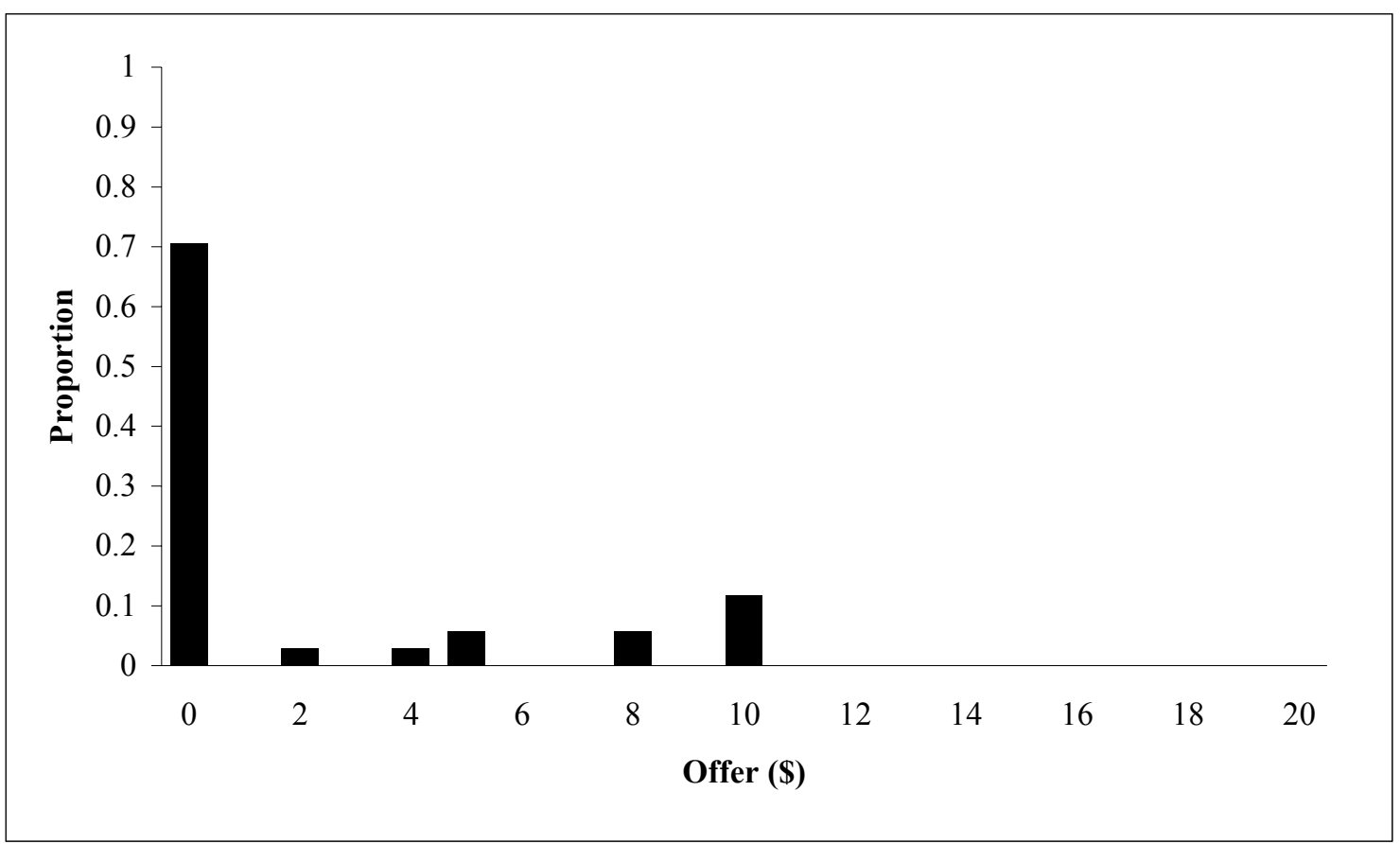

Figure 2B. Experiment S\$20 (Symmetric Earnings of \$20)

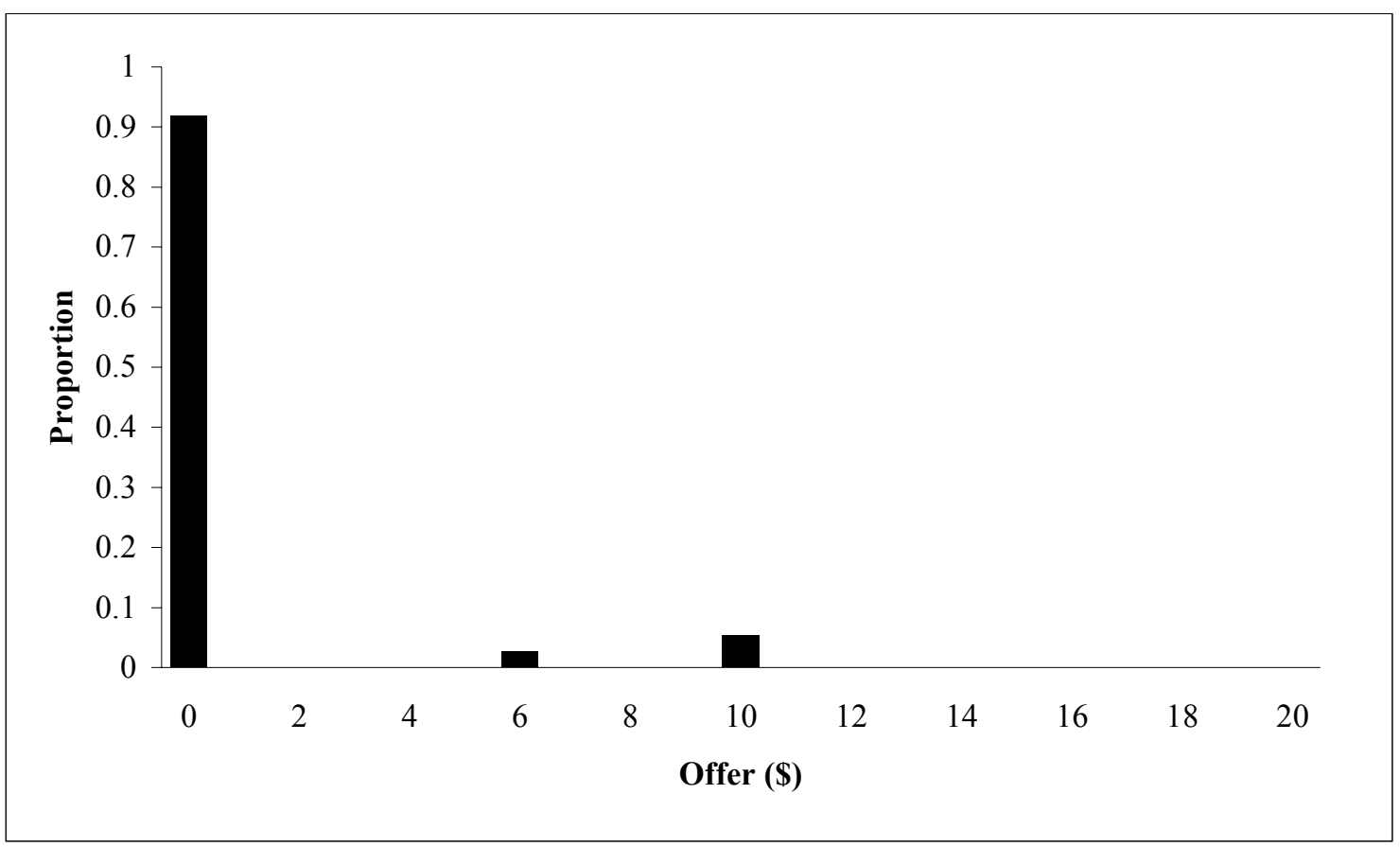


Figure 3A. Experiment A\$100 (Asymmetric Earnings of \$100)

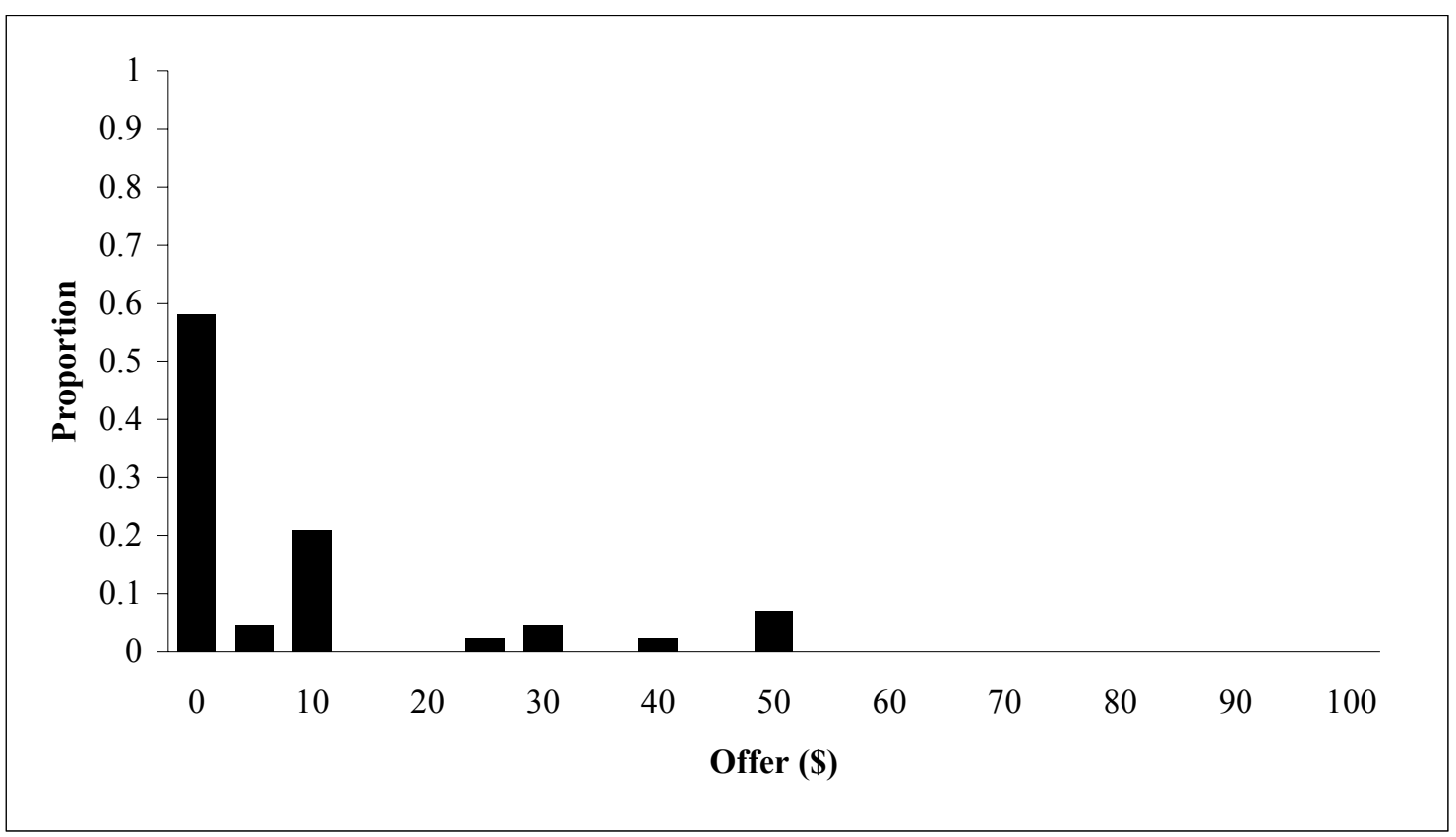

Figure 3B. Experiment S\$100 (Symmetric Earnings of \$100)

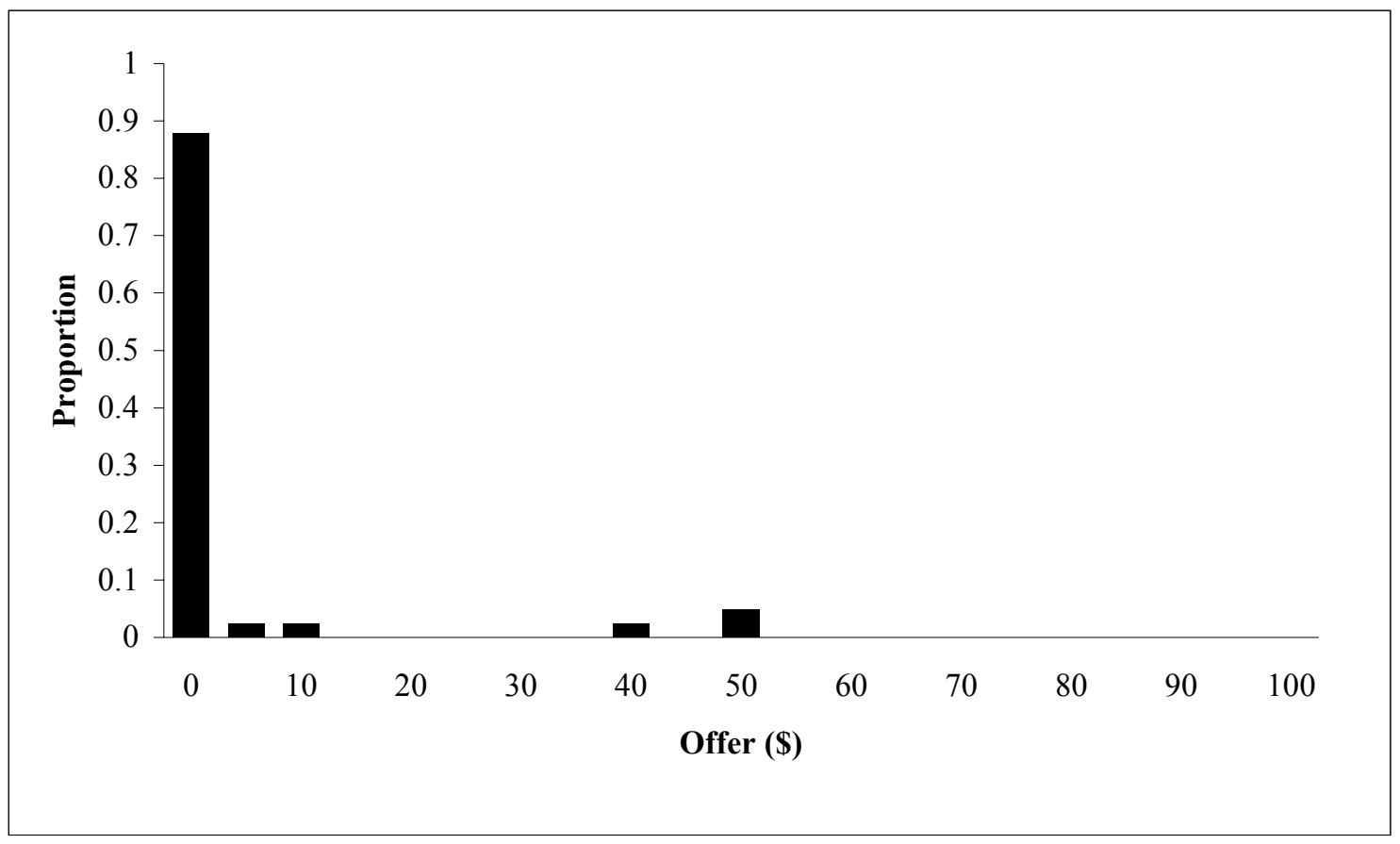

